Mal J Nutr 27(2): 279-291, 2021

\title{
Association between nutrition knowledge and nutrition practice among Malaysian adolescent handball athletes
}

\author{
Normah Jusoh ${ }^{1 *}$, Jeffrey Low Fook Lee ${ }^{1}$, Ruaibah Yazani Tengah ${ }^{1}$, Siti Hartini \\ Azmi $^{1}$ \& Adang Suherman ${ }^{2}$
}

${ }^{1}$ Faculty of Sports Science and Coaching, Universiti Pendidikan Sultan Idris, 35900 Tanjung Malim, Perak, Malaysia; ${ }^{2}$ Department of Health Education and Recreation, Universitas Pendidikan Indonesia, Bandung, Indonesia

\begin{abstract}
Introduction: Previous literature suggests that good nutrition knowledge does not necessarily translate into desired eating behaviours among adolescent athletes, which may affect their sports performance. The purposes of the study were twofold, which were to examine nutrition knowledge and practice between the sexes, and to evaluate the magnitude of relationship between nutrition knowledge and practice among adolescent handball athletes in Malaysia. Methods: Three hundred and twelve male and female adolescent handball players competing in a national level competition voluntarily participated in this study. The participants were asked to complete a questionnaire which consisted of items on their demographic information and about their nutrition knowledge and eating practices. Independent $t$-test and Pearson's correlation were used to compare nutrition knowledge and practice between the sexes and to describe the relationship between variables, respectively. Results: The results showed that there were no significant differences $(p>0.05)$ observed for nutrition knowledge and practice between the sexes. Besides, the results demonstrated that nutrition knowledge had a significant but weak positive correlation with eating habit $(r=0.114, p=0.003)$ among the athletes. Conclusion: This study showed that nutrition knowledge and practice were moderately adequate, and that knowledge does not necessarily translate into good dietary practices. Therefore, the athletes would benefit from a comprehensive and innovative nutrition education, a strategy which warrants further investigation.
\end{abstract}

Keywords: nutrition knowledge, dietary practice, young athletes, handball

\section{INTRODUCTION}

Nutrition is one of the determinants for sports performance among athletes. Nutritional requirement changes as an individual move through different life stages. As such, adolescent athletes require unique nutritional consideration because they undergo altered hormonal, metabolism, and body composition changes following the onset of puberty. Young athletes need adequate energy to fulfil the requirements for both growth and development, as well as the demands for daily training and competition. Indeed, the Sports Dietitians Australia (SDA) has established a position statement about nutrition for adolescent athletes to address the aforementioned

\footnotetext{
*Corresponding author: Assoc. Prof. Dr. Normah Jusoh

Faculty of Sports Science and Coaching, Universiti Pendidikan Sultan Idris 35900 Tanjung Malim, Perak, Malaysia

Tel: +601548797193; Fax: +601548797288; Email: normah@fsskj.upsi.edu.my

doi: https: / /doi.org/10.31246/mjn-2020-0113
} 
issue. SDA recommends that energy intake from carbohydrate, fat and protein should follow the guidelines set for adult athletes with some adjustments to match the energy demands (Desbrow et al., 2019).

Muia et al. (2016) stated that it is common for adolescent athletes to experience inadequate energy due to heavy training. Nutrition adequacy depends on many factors such as nutrition knowledge, eating habit, training intensity, socioeconomic status, access to foods, to name a few. Much of the literature showed that athletes do not have adequate nutritional status for their respective sports because they do not follow the dietary guidelines (Heikura et al., 2017). For instance, Jenner and colleagues (2019) concluded that professional and semi-professional team sport athletes did fulfil the recommendations for protein and fat intakes during training and competition, but not energy and carbohydrate recommendations. It is crucial that athletes consume sufficient energy and micronutrients to achieve optimal sports performance and to enhance recovery.

Likewise, nutritional inadequacy among adolescent athletes is caused by poor nutrition knowledge (Spronk et al., 2015; Andrews et al., 2016; Condo et al., 2019). Lack of nutrition knowledge may be attributed to incorrect information received by the athletes. Generally, coaches are the person in closest contact with the athletes, thus athletes often rely on their coaches for nutrition information. However, a systematic review on athletes' and coaches' nutrition knowledge showed that coaches were not the best source of valid information for general and sports nutrition (Trakman et al., 2019). TorresMcGehee et al. (2012) compared the nutrition knowledge among 579 studentathletes, team coaches, athletic trainers, and strength conditioning experts, and found that coaches and student-athletes had lower nutrition score than the other two groups.

Besides, disparities in knowledge level and practice between the sexes were observed in a few studies. Spronk et al. (2015) showed that Australian elite females were more knowledgeable in terms of nutrition knowledge and diet quality compared to their male counterparts. In contrast, Hull et al. (2017) reported that the National Collegiate Athletic Association (NCAA) male athletes had less favourable eating habits than female athletes, who have associated body image and dieting concerns. Therefore, in order to maintain an ideal weight, they tend to practise healthy diet, which requires a good knowledge in nutrition. However, another study by Saribay \& Kirbas (2019) showed otherwise. They evaluated the knowledge between adolescent male and female athletes in Turkey and revealed that no significant differences existed in nutrition knowledge between the sexes. These inconsistencies in data warrant further studies to assess whether the levels of nutrition knowledge and practice may differ between the sexes.

Nutrition knowledge is often associated with healthy dietary practices. However, a comprehensive review on nutrition knowledge and dietary intake suggested that athletes have adequate nutrition knowledge, but it does not always translate into proper nutrition practices (Spronk et al., 2015). According to the Health Belief Model, a person's willingness to change their health behaviour depends on their health perception. This portrays that knowledge should be a powerful tool to alter athletes' perception about nutrition and thus habit, but unfortunately, this was not the case as shown by previous literature. This situation is not only prevalent among athletes, but also seen in medical students in a few countries, 
such as Australia (Perlstein et al., 2017) and Saudi Arabia (Eman et al., 2015), whom we assume are groups of people who would adhere to the knowledge they possess to serve as role models for their patients. It is prudent to suggest that all population, regardless of their socioeconomic status, require solid nutrition knowledge to help them make wise food selections for healthy living and to sustain physical activity performance. Thus, it warrants further studies to assess whether the level of nutrition knowledge may influence dietary habits.

In Malaysia, there is still a scarcity of data regarding this issue, particularly in young athletes under 18 years old. Much of the available data were derived from adult athletes and non-athlete population (Razalee \& Tan, 2014; Siti Soraya et al., 2018). Therefore, this study aimed to compare the levels of nutrition knowledge and practice between male and female adolescent handball athletes competing in a national tournament, as well as to examine whether correlation exists between these variables. We hypothesised that there will be no significant differences in terms of nutrition knowledge and practice between the sexes, and that no significant association will be observed between nutrition and dietary practice among the athletes.

\section{MATERIALS AND METHODS}

\section{Study population}

A cross-sectional study was conducted among the adolescent handball athletes aged between 13 to 18 years old (under 18 years old category) who participated in the national level Majlis Sukan Sekolah Malaysia (MSSM) competition for school athletes in 2019. MSSM is a prestigious tournament which comprises of the best athletes representing all 14 states of Malaysia. All athletes have undergone systematic training sessions with their own team coach before the competition. A total of 336 athletes were asked to participate in this study and the response rate was $92.8 \%$. There were 155 male and 157 female athletes who agreed to volunteer for this study. The sample size of 312 was considered sufficient to detect a difference at a significance level of 0.05 and $95 \%$ confidence based on Krecjie \& Morgan (1970). Parental and athletes' informed consents were obtained after being given verbal and written information about the study. The study protocol was reviewed and approved by the Universiti Pendidikan Sultan Idris Ethical Advisory Committee (Ethical approval serial no: 2019-003701).

\section{Instrument}

In this descriptive study, the participants were asked to complete a questionnaire adapted from Razalee \& Tan (2014). The permission to use and modify the questionnaire was obtained from the original authors before commencing the study. Before administering it to the participants, the questionnaire was evaluated for content validity by three experts in nutrition. The content validation index (CVI) of the revised questionnaire scored 0.98 for relevance and ambiguity, and 0.99 for clarity and simplicity. The validated questionnaire was then piloted among 30 young athletes to assess its reliability. The $r$-value for the questionnaire was 0.89 as calculated using Cronbach's alpha, suggesting that the questionnaire had high internal reliability.

The participants answered their demographic information in Part A, while Parts B and C consisted of items about nutrition knowledge and practices, respectively. There were 11 statements about nutrition knowledge with True and False options. A correct response was coded as 1 and 0 for incorrect answer. The total score of 11 
Table 1. Source of nutrition information of the participants $(n=312)$

\begin{tabular}{lcc}
\hline Source of nutrition information & Frequency $(n)$ & Percentage $(\%)$ \\
\hline Internet & 170 & \\
$\quad$ Yes & 142 & 54.4 \\
$\quad$ No & 96 & 45.5 \\
Magazines, newspapers & 216 & 30.7 \\
$\quad$ Yes & 7 & 69.3 \\
$\quad$ No & 305 & 2.2 \\
Social media & & 97.8 \\
$\quad$ Yes & 31 & \\
$\quad$ No & 281 & 9.9 \\
Nutritionist & & 90.1 \\
$\quad$ Yes & 90 & 28.8 \\
$\quad$ No & 222 & 71.2 \\
Doctors & & \\
$\quad$ Yes & 181 & 58.0 \\
$\quad$ No & 131 & 42.0 \\
Physical and health education class & & \\
$\quad$ Yes & 286 & 81.7 \\
$\quad$ No & 26 & 8.3 \\
Team coach & & \\
$\quad$ Yes & & \\
$\quad$ No & & \\
\hline
\end{tabular}

items were converted into percentage and characterised as poor nutrition knowledge (50\% and below), moderate (51-79\%), and good knowledge (80$100 \%$ ), which was predetermined prior to the study.

To measure nutrition practice, 14 items were asked with a scale ranging from 1 (never; does not occur at all), 2 (sometimes; 1-2 day/week), 3 (often; 3-4 day/week), and 4 (always; 5-7 day/ week). There were eight statements about positive nutrition habit and the score was given in descending order from 4 (always) to 1 (never). On the contrary, for the remaining six items of undesirable behaviours, the score was reversed ranging from 1 for inappropriate to 4 for very appropriate practice. The possible total scores for nutrition practice range from 14 to 56. The higher the total score, the better the dietary habits of the participants.

\section{Procedure}

Data of the athletes participating in the
2019 MSSM Handball Championship was obtained from the Education Department of Perak as event coordinator. The coaches of each state were informed about the study and were asked for their permission to allow their athletes to participate in the study on voluntary basis. During the seven days of the tournament period, the athletes were recruited and informed consent was obtained from the athletes and their parents.

Body weight and height were measured closest to $0.1 \mathrm{~kg}$ and $0.1 \mathrm{~cm}$ using calibrated digital weighing scale (Omron HN-288, Germany) and stadiometer (Charder HM-200P, USA), respectively. The participants were given approximately 20 minutes to answer the questionnaire in a quiet area to minimise interference from the crowd who were watching the games.

\section{Statistical analysis}

Data analysis was conducted using the Statistical Package for Social Sciences 
Table 2. Frequency and percentages of correct answer on nutrition knowledge of the athletes $(n=312)$

\begin{tabular}{|c|c|c|}
\hline \multicolumn{2}{|c|}{ Item } & \multirow{2}{*}{$\begin{array}{c}\text { Correct } \\
\text { responses } \\
n(\%)\end{array}$} \\
\hline 1. & Skipping breakfast can negatively affect athletic performance & \\
\hline & Nutrition affects sports performance & $294(94.2)$ \\
\hline & $\begin{array}{l}\text { According to the Food Pyramid Malaysia, one should consume 4-8 } \\
\text { servings from the bread, cereal, rice and pasta group }\end{array}$ & $191(61.2)$ \\
\hline & $\begin{array}{l}\text { According to the Food Pyramid Malaysia, one should consume } 2 \\
\text { servings of fruits and } 3 \text { servings of vegetables }\end{array}$ & $261(83.7)$ \\
\hline 5. & $\begin{array}{l}\text { According to the Food Pyramid Malaysia, one should consume 2-3 } \\
\text { servings from the dairy group }\end{array}$ & $218(69.9)$ \\
\hline 6. & $\begin{array}{l}\text { According to the Food Pyramid Malaysia, one should consume } 1 / 2-2 \\
\text { servings from the meat group }\end{array}$ & $226(72.4)$ \\
\hline 7. & Eating breakfast can improve concentration & $297(95.2)$ \\
\hline & If you are not thirsty, then you must not be dehydrated & $70(22.4)$ \\
\hline & Athletes should not consume drinks during training & $125(40.1)$ \\
\hline & $\begin{array}{l}\text { Coaches should not allow the athletes to consume drinks during } \\
\text { training }\end{array}$ & $140(44.8)$ \\
\hline & $\begin{array}{l}\text { Coaches should not allow the athletes to consume drinks during } \\
\text { competition }\end{array}$ & $147(47.0)$ \\
\hline
\end{tabular}

(SPSS) version 23.0 (IBM Corp, Chicago, USA). All data sets were found to have a normal distribution using the ShapiroWilk test. Parametric data were reported as mean \pm standard deviation $(S D)$. Descriptive data were presented as frequency and percentage. Independent t-test was used to compare the nutrition knowledge and practice between the sexes, while correlations between variables were determined by Pearson's correlation test. A significant level was set at $p<0.05$.

\section{RESULTS}

One hundred fifty-five males and 157 female adolescent athletes participated in this study. They had a mean age of $16 \pm 1$ years, height and body weight of $165.9 \pm 0.9 \mathrm{~cm}$ and $62.2 \pm 12.9 \mathrm{~kg}$, respectively. Table 1 shows the source of nutrition information of the participants. The participants listed team coaches $(91.7 \%)$ as the most frequent source, followed by parents (68.3\%), physical and health education class $(58.0 \%)$, internet
(54.5\%), doctors (28.8\%), magazines and newspapers $(30.7 \%)$, nutritionist $(9.9 \%)$, and social media (2.2\%).

The frequency and percentages of correct answers for nutrition knowledge items are listed in Table 2. More than 60\% of the participants had correct answers on the importance of breakfast and the Malaysian Food Pyramid. However, less than $50 \%$ of them responded correctly on hydration and fluid intake for training and competition. In terms of nutrition knowledge level, $55.3 \%$ of 312 participants scored well in nutrition knowledge, meanwhile $43.1 \%$ and $1.6 \%$ of them had moderate and poor nutrition knowledge, respectively.

Table 3 shows the frequency and percentages of nutrition practice among the participants. Majority of the participants reported good dietary habit on items such as consumed breakfast regularly $(74.4 \%)$, did not skip three meals a day $(70.6 \%)$, ate enough fruits $(78.8 \%)$, consumed a lot of plain water $(95.8 \%)$, and took sufficient carbohydrate $(81.1 \%)$ 


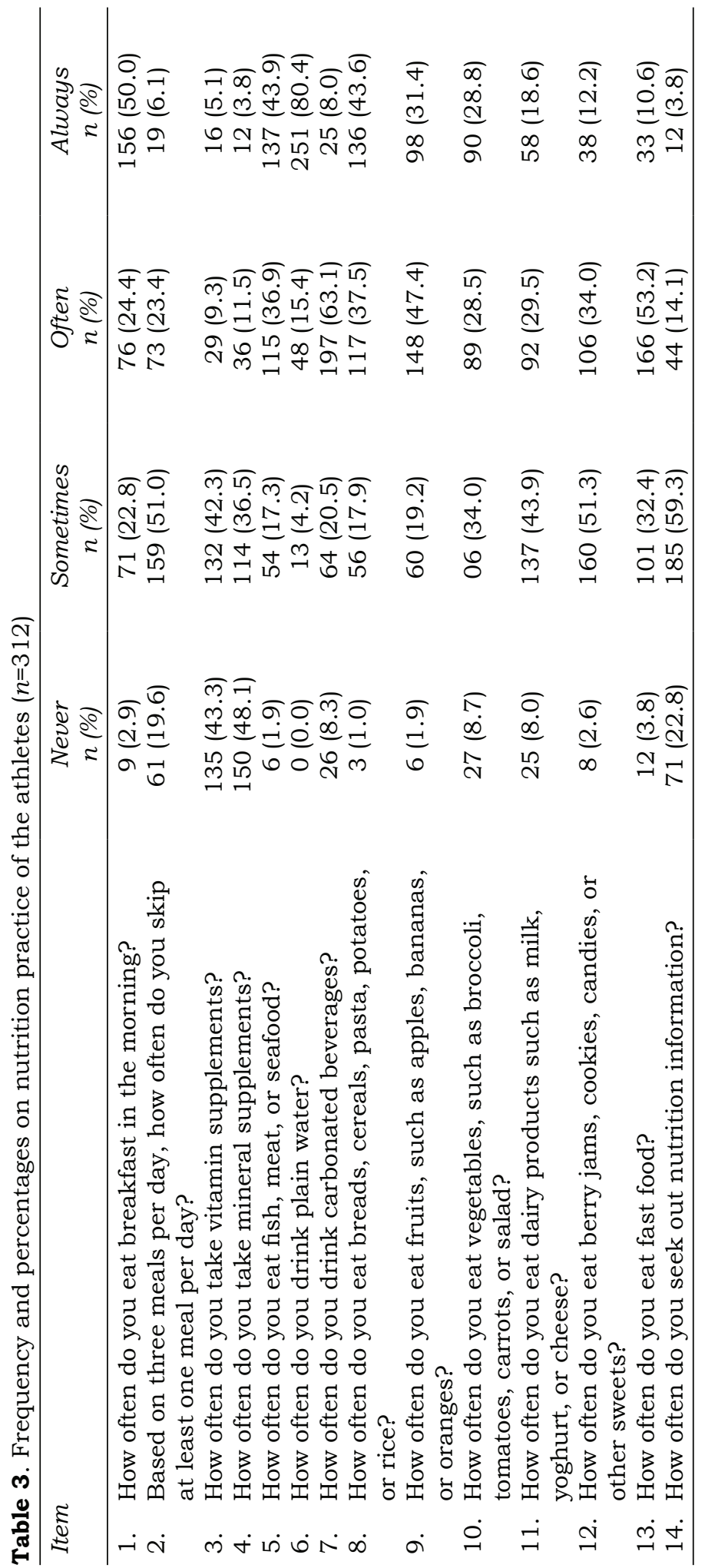


Table 4. Nutrition knowledge and practice between the sexes $(n=312)$

\begin{tabular}{lcccc}
\hline Variables & $\begin{array}{c}\text { Male athletes } \\
(n=155) \\
\text { Mean } \pm S D\end{array}$ & $\begin{array}{c}\text { Female athletes } \\
(n=157) \\
\text { Mean } \pm S D\end{array}$ & 95\% CI & p-value \\
\hline $\begin{array}{l}\text { Nutrition knowledge } \\
\text { (number of correct } \\
\text { answers) }\end{array}$ & $8.5 \pm 1.4$ & $8.7 \pm 1.3$ & $(-1.894,0.049)$ & 0.179 \\
$\begin{array}{l}\text { Nutrition knowledge } \\
\text { (\% of correct } \\
\text { answers) }\end{array}$ & $77.3 \pm 12.1$ & $78.6 \pm 13.1$ & $(-0.093,0.494)$ & 0.109 \\
$\begin{array}{l}\text { Nutrition practice } \\
\text { score }\end{array}$ & $36.7 \pm 5.0$ & $37.6 \pm 3.6$ & $(-0.842,4.489)$ & 0.076 \\
\hline
\end{tabular}

and protein sources (80.8\%). However, $71.1 \%$ of the participants reportedly consumed carbonated beverages quite regularly, $42.7 \%$ seldom ate vegetables, $46.2 \%$ took sweets, $63.5 \%$ ate fast foods, and only $17.9 \%$ of them looked for information about nutrition.

Table 4 presents the mean differences in nutrition knowledge and practice between the sexes. Both groups had no significant differences in mean score of nutrition knowledge in terms of numbers and percentages of correct answers. On average, they correctly answered eight out of 11 questions about the food pyramid, the importance of breakfast, as well as dietary intake for sports performance. The mean score for percentages of correct answer for male and female athletes were $77.3 \pm 12.1 \%$ and $78.6 \pm 13.1 \%$, respectively, indicated that both groups of athletes had

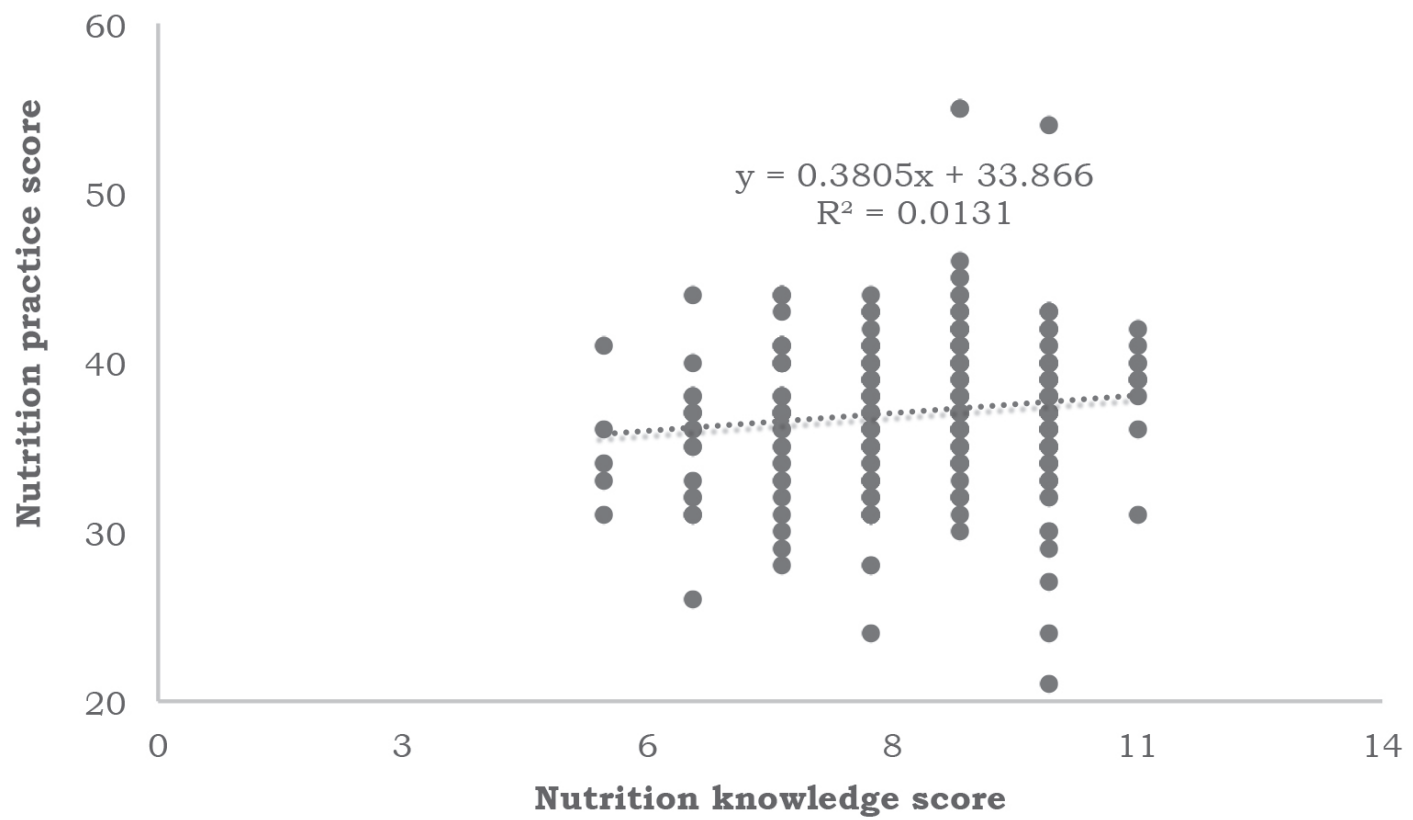

Figure 1. Relationship between nutrition knowledge and practice among adolescent handball athletes $(n=312)$ 
moderate level of nutrition knowledge. Furthermore, the findings on nutrition practice showed that female athletes scored higher than their male counterparts, but the difference was not significant. Both groups only scored a little higher than $50 \%$ of the total mark, which inferred that they did not practise proper eating habits.

A correlation between nutrition knowledge and practice of the athletes is shown in Figure 1. Pearson's correlation test reported a significant but weak positive relationship between these variables $(r=0.114, \quad p=0.003)$. This suggests that nutrition knowledge had a small, yet significant influence on the dietary habits of athletes.

\section{DISCUSSION}

Overall, this study revealed that both male and female adolescent handball athletes had moderate level of nutrition knowledge and practice, which were not significantly different between groups. Although they had moderate nutrition knowledge, it only contributed slightly to their dietary habits.

Most participants gave a correct answer to an average of eight out of 11 questions tested about general nutrition and sports nutrition, giving a mean knowledge score within the range of $77-78 \%$, which is at a moderate level. Many of the participants in our study knew that skipping breakfast has a negative effect on cognitive and sports performance, and were aware about meal suggestions based on the food pyramid. However, they were lacking in terms of the importance of fluid intake to prevent dehydration during training (Table 2). The American College of Sports Medicine (ACSM) has established in a position stand on fluid replacement that athletes should drink fluid sufficiently before and during training or competition to prevent at least $2 \%$ body mass loss in order to sustain sports performance (Sawka et al., 2007).

Our results were consistent with previous literature. For instance, Walsh et al. (2011) who evaluated the nutrition knowledge among 203 senior school male rugby athletes in Ireland concluded that the athletes had poor knowledge of the foods required for refuelling, appropriate use of sports drinks, and the role of protein in muscle formation, with an overall knowledge score of $59.6 \%$. Similarly, Heikkila et al. (2018) revealed that the nutrition knowledge among young Finnish endurance athletes was relatively low $(73 \%)$, particularly in the area of nutrition recommendations for endurance athletes and dietary supplements. It is very important for athletes to have correct information on the nutrition recommendations for their sports to ensure they get sufficient energy to perform optimally on-field. Indeed, ACSM and the Academy of Nutrition and Dietetics highly recommend that athletes should be referred to registered dietitians and nutritionists for a personalised nutrition plan because well-chosen nutrition strategies are crucial to athletes' performance and recovery (Thomas, Erdman \& Burke, 2016).

Results on the sources of nutrition information showed that $91.7 \%$ of adolescent handball athletes get their nutrition information from their coaches. Some studies have pointed out that team coaches may not be the best person to consult regarding nutrition as they may not have the proper knowledge necessary to give accurate advice to the athletes (Torres-McGehee et al., 2012; Botsis \& Holden, 2015). Even though our study did not assess the nutrition knowledge of coaches, this issue remains a concern since coaches are the nearest person and are an important resource for the athletes as shown in our 
study. The National Coaching Academy of National Sports Institute (AKK-ISN) of Malaysia has been continually offering Sports Science courses (Level 1 to Level 3), which comprise all elements of sports sciences, including sports nutrition, to coaches. But, up to date, no data is available on how many coaches have participated in and benefited from these courses. Therefore, future investigation is necessary to examine the Malaysian coaches' nutritional knowledge and to determine whether or not it is sufficient to avoid misconception among athletes.

Besides coaches, online platform was also a popular source of nutrition information among half of our participants, which ranked third in the list $(54.4 \%)$. During this digital technology era, it is obvious that most nutrition information is widely available online. However, less is known about the information provider, which may lead to misinformation among the readers (Kitchen, Harle \& Li, 2014). Therefore, digital literacy should be introduced to young athletes to help them make better judgement towards the abundance of nutrition information available online. With the enthusiasm and engagement of the young population towards digital technology, it is timely for nutritionists and dietitians to make full use of the online platform in disseminating correct information about nutrition.

It has been shown that from our study and previous literature that adolescent athletes are struggling to acquire different aspects of nutrition knowledge. Despite that, a similar trend has been observed that most athletes have inadequate level of nutrition knowledge. Without good knowledge, it is impossible to change the attitude and dietary habit to a better one. An individual must possess health literacy in order to appreciate nutrition knowledge. According to Peerson \& Saunders (2009), health literacy is one's ability to obtain, read, understand, and use health information and services to make appropriate everyday health care decisions. The National Health and Morbidity Survey (NHMS) 2019 reported that one in three individuals in Malaysia had low health literacy (IPH, 2020). One of the factors that affects health literacy is access to information. Therefore, with the progress in digital technology, innovative nutrition education strategies utilising online access are needed to improve the knowledge of athletes.

Moreover, the results of nutrition practice showed that our athletes had practised healthy dietary habits moderately with regards to breakfast consumption and fluid intake during training and competition. Many studies showed similar trends in eating habit among athletes. Condo et al. (2019) who studied the nutritional intake and sports nutrition knowledge among adult female Australian athletes concluded that their athletes did not practise proper nutritional habits as there were inadequate intakes of carbohydrate and calcium. Another study by Normah (2014) on the hydration knowledge, attitude and fluid consumption behaviour among student athletes in a sport school in Malaysia showed that the athletes had misconception about the use of salt tablets to prevent dehydration, inappropriate use of thirst as an indicator for dehydration, and the need to consume sports drinks within two hours after exercise or training. ACSM has established a statement that sports drink is highly recommended for individuals undergoing training or exercise of more than an hour because it offers glucose for recovery, sodium to retain body water, and of course, fluid to replace water loss (Sawka et al., 2007).

The results of the current investigation found that there were no significant differences in nutrition 
knowledge and practice between male and female athletes. To the best of our knowledge, this was the first study that looked into the nutrition knowledge and practice among competitive adolescent handball athletes in Malaysia, and the results obtained were quite the opposite to cited literatures from other countries. Hull et al. (2016) who conducted a survey among male and female NCAA Division 1 athletes concluded that women tend to have more desirable habits such as cooking meals for themselves and not skipping breakfast. In contrast, male athletes showed higher occurrence of undesirable eating behaviours such as consuming fast foods or restaurant meals more frequently and having a higher consumption of alcohol during competitive season. On the other hand, Fortes et al. (2014) reported that female athletes had higher frequency of highcalorie diet restriction and were more dissatisfied with their body image compared to male adolescent athletes, which may lead to eating disorders. In our study, no differences were observed in terms of nutrition knowledge and practice between the sexes. This is likely due to the types of sports they play, namely team sport. Thus, they would not have much concerns about weight management and physical appearance as long as they can perform well in the tournament, and thus have less risk of engaging in unhealthy eating habits. Evidence has suggested that most unhealthy eating behaviours occur in sports that emphasise leanness or weight category, particularly in female athletes (Fortes et al., 2014). Therefore, this topic remains inconclusive and requires additional investigation, in particular the comparison of dietary practices among athletes from different sports categories.

Furthermore, findings of the current study concluded that there was a significantly weak positive relationship between nutrition knowledge and practice among the athletes. Athletes who have higher knowledge would presumably practise desirable eating habits, but the relationship did not hold true for the majority of our respondents. If we look at the results on the sources of nutrition information, $58 \%$ of our participants claimed that they obtained their nutrition information from attending physical and health education classes. In Malaysia, nutrition education is embedded in the school curriculum and taught in Health Education in both primary and secondary schools. The lengthy period of nutrition exposure should have become a good nutrition base for our athletes. However, it is not assured that they will gain and adhere to the knowledge despite having attended nutrition-related courses over a period of school years. This statement is supported by a study from Andrews et al. (2016), who examined sports nutrition knowledge among 123 Division 1 NCAA student-athletes. They concluded that previous exposure to nutrition course did not significantly improve nutrition knowledge among athletes, and that this was probably because they were less motivated to focus on the nutrition component of their own sport and performance.

In fact, some studies also showed similar findings as our study, that even though the subjects had adequate knowledge, it did not translate into favourable eating behaviours (Lohman, Carr \& Condo, 2019; Walsh et al., 2011). They reasoned that the misalignment of this concept was due to attitude towards food intake and eating behaviours. Walsh et al. (2011) measured nutrition knowledge, attitude and behaviour among adolescent rugby athletes and concluded that they demonstrated poor knowledge and nutrition practice 
despite having positive attitude towards nutrition. Our study did not measure the attitude of the athletes towards eating behaviour, but based on previous research, we speculate that the absence of good attitude towards nutrition among our athletes may have also contributed to inadequate knowledge and improper dietary practices. This highlights the need for some educational intervention to increase awareness towards nutrition and desirable dietary practices among adolescent athletes. An example of educational strategy which could be considered by educators is game-based learning. Many literature in the field of information technology, computer science, game design and engineering have shown the effectiveness of gamification in motivating and engaging students compared to traditional lectures (Licorish et al., 2019). Johnson and colleagues (2016) concluded from their systematic review that out of 19 papers presenting empirical evidence about gamification for health and wellbeing, 59\% reported positive outcomes, while $41 \%$ had moderate to lower quality of evidence. Therefore, research on gamification in health and well-being is warranted to improve the knowledge and behaviours of learners.

\section{Limitation of the study}

Despite offering some new insights into the knowledge and practice of nutrition among competitive adolescent athletes, our study also had some drawbacks. The use of self-administered report has been argued as being less trustworthy because the participants may not respond honestly to the questionnaire (Torstveit, Rosenvinge \& Sundgot-Borgen, 2008). However, our study used a large sample involving more than 300 respondents in a field-setting, thus, a questionnaire was the recommended instrument because it was easy, convenient and inexpensive. In fact, we had at our very best effort explained the questionnaire verbally and with written instruction to the participants, and made sure they answered in our presence in designated areas. Another limitation of the study was that we limited the data collection to one specific sport, which is handball. Therefore, our data only represent the nutrition knowledge and practice of adolescent team sport athletes and may not be true for athletes in the individual sport categories. Future studies should include a more comprehensive sample of competitive adolescent athletes from different sport categories.

\section{CONCLUSION}

This was the first study to assess the relationship between nutrition knowledge and practice among competitive adolescent handball athletes in Malaysia. This study demonstrated a significant but weak positive relationship between nutrition knowledge and practice in the athletes. The overall nutrition knowledge and practice were similar in both sexes, with only a moderate level of understanding of nutrition and practice of desirable behaviours, highlighting the need for nutrition education interventions. Future research should consider the role of health literacy in order to strengthen understanding of nutrition knowledge and enhance translation of knowledge into healthful practices that will benefit the athletes' well-being and sports performance.

\section{Acknowledgement}

The authors are grateful to the Universiti Pendidikan Sultan Idris for the financial support of the study (Grant no: 2019-0096-107-01). We would also like to extend our highest gratitude to all participants in this study, as well as to the team coaches for giving permission to access their athletes. 


\section{Authors' contributions}

NJ, principal investigator, conceptualised and designed the study, prepared the draft of the manuscript, and reviewed the manuscript; JLFL, led the data collection, advised on data analysis and interpretation, and reviewed the manuscript; RYT, assisted in data collection and reviewed the manuscript; SHA, assisted in data collection and reviewed the manuscript; AS, advised on data analysis and interpretation, and reviewed the manuscript.

\section{Conflict of interest}

The authors have no conflict of interest or relevant financial relationship in this study.

\section{References}

Andrews A, Wojcik JR, Boyd JM \& Bowers CJ (2016). Sports nutrition knowledge among MidMajor Division I University Student-Athletes. $J$ Nutr Metabolism 2016:3172460. https:/ / doi. org/10.1155/2016/3172460

Botsis AE \& Holden S (2015). Nutritional knowledge of college coaches. Sport Sci Rev 24:193-200.

Condo D, Lohman R, Kelly M \& Carr A (2019). Nutritional intake, sports nutrition knowledge and energy availability in female Australian rules football players. Nutrients 11(5):971. https://doi.org/10.3390/nu11050971

Desbrow B, Burd NA, Tarnopolsky M, Moore R \& Elliot-Sale KJ (2019). Nutrition for special populations: Young, female, and masters athletes. Int J Sport Nutr Exerc Metab 29(2):220227.

Eman MA, Hend A, Asma Z, Dalya A, Maria B \& Nojoud BH (2015). Knowledge, attitude and practice of dietary and lifestyle habits among medical students in King Abdul Aziz University, Saudi Arabia. Int J Nutr Food Sci 4(6): 650-655.

Fortes LS, Kakeshita IS, Almeida SS, Gomes AR \& Ferreira MEC (2014). Eating behaviours in youths: A comparison between female and male athletes and non-athletes. Scan J Med Sci Sports 24(1):e62-e68. https://doi: 10.1111/ sms. 12098

Heikkilä M, Valve R, Lehtovirta M \& Fogelholm M (2018). Nutrition knowledge among young Finnish endurance athletes and their coaches. Int J Sport Nutr Exerc Metab 28(5):522527.

Heikura IA, Stellingwerff T, Mero AA, Uusitalo ALT \& Burke LM (2017). A mismatch between athlete practice and current sports nutrition guidelines among elite female and male middle- and long-distance athletes. Int $J$ Sport Nutr Exerc Metab 27(4):351-360.
Hull MV, Neddo J, Jagim AR, Oliver JM, Greenwood M \& Jones MT (2017). Availability of a sports dietitian may lead to improved performance and recovery of NCAA division I baseball athletes. J Int Soc Sports Nutr 14:29. https://doi:10.1186/s12970-017-0187-6

Jenner SL, Buckley GL, Belski R, Devlin BL $\&$ Forsyth AK (2019). Dietary intakes of professional and semi-professional team sport athletes do not meet sport nutrition recommendations: A systematic literature review. Nutrients 11(5):1160. https://doi. org/10.3390/nu11051160

Johnson D, Deterding S, Kuhn KA, Staneva A, Stoyanov S, \& Hides L (2016). Gamification for health and wellbeing: A systematic review of the literature. Internet Interventions 6:89-106.

Kitchens B, Harle CA \& Li S (2014). Quality of health-related online search results. Decis Support Syst 57:454-462.

Krejcie RV \& Morgan DW (1970). Determining sample size for research activities. Educ Psychol Meas 30(3):607-610.

Licorish SA, George JL, Owen HE, Daniel B (2017). "Go Kahoot!" enriching classroom engagement, motivation and learning experience with games. In Proceedings of the 25th International Conference on Computers in Education, (ICCE 2017) (pp. 755-764). Christchurch, New Zealand: Asia-Pacific Society for Computers in Education

Lohman R, Carr A \& Condo D (2018). Nutritional intake in Australian football players: Sports nutrition knowledge and macronutrient and micronutrient intake. Int $J$ Sport Nutr Exerc Metab 29(3):289-296.

Muia EN, Wright HH, Onywera VO \& Kuria EN (2016). Adolescent elite Kenyan runners are at risk for energy deficiency, menstrual dysfunction and disordered eating. $J$ Sports Sci 34(7):598-606.

IPH (2020). National Health and Morbidity Survey (NHMS) 2019: Non-communicable diseases, healthcare demand, and health literacy-Key Finding. Institute for Public Health, Ministry of Health Malaysia, Kuala Lumpur.

Normah J (2014). Relationship between hydration status, hydration knowledge and fluid intake behaviour among school athletes of selected Perak sport schools. Jurnal Sains Sukan \& Pendidikan Jasmani 3(1):11-19.

Peerson A \& Saunders M (2009). Health literacy revisited: what do we mean and why does it matter? Health Promot Int 24(3):285-96. 
Perlstein R, McCoombe S, Macfarlane S, Bell AC \& Nowson C (2017). Nutrition practice and knowledge of first-year medical students. $J$ Biomed Sci 2017. h t t p s : / / d o i . org/10.1155/2017/5013670

Razalee S \& Tan YY (2014). Dietary habits and nutrition knowledge among athletes and nonathletes in National University of Malaysia (UKM). Pak $J$ Nutr 13:752-759.

Saribay AK \& Kirbas S (2019). Determination of nutrition knowledge of adolescents engaged in sports. Univers $J$ Educ Res 7:40-47.

Sawka MN, Burke LM, Eichner ER, Maughan RJ, Montain SJ \& Stachenfeld NS (2007). American College of Sports Medicine position stand. Exercise and fluid replacement. Med Sci Sports Exerc 39(2):377-90.

Siti Soraya ME, Hazizi AS, Mohd Nasir MT \& Zubaidah J (2018). Effects of sports nutrition education intervention on sports nutrition knowledge, attitude and practice, and dietary intake of Malaysian team sports athletes. Mal J Nutr 24(1):103-116.

Spronk I, Heaney SE, Prvan T \& O'Connor HT (2015). Relationship between general nutrition knowledge and dietary quality in elite athletes. Int $J$ Sport Nutr Exerc Metab 25(3):243-251.
Thomas DT, Erdman KA \& Burke LM (2016). Position of the Academy of Nutrition and Dietetics, Dietitians of Canada, and the American College of Sports Medicine: Nutrition and athletic performance. $J$ Acad Nutr Diet 116(3):501-528.

Torres-McGehee TM, Pritchett KL, Zippel D, Minton DM, Cellamare A \& Sibilia M (2012). Sportsnutrition knowledge among collegiate athletes, coaches, athletic trainers, and strength and conditioning specialists. $J$ Athl Train 47(2):205-211.

Torstveit MK, Rosenvinge JH \& Sundgot-Borgen $J$ (2008). Prevalence of eating disorders and predictive power of risk models in female elite athletes: a controlled study. Scand J Med Sci Sports 18(1):108-118.

Trakman GL, Forsyth A, Devlin BL \& Belski R (2016). A systematic review of athletes' and coaches' nutrition knowledge and reflections on the quality of current nutrition knowledge measures. Nutrients 8(9): 570. https://doi. org/10.3390/nu8090570

Walsh M, Cartwright L, Corish C, Sugrue S \& Wood-Martin R (2011). The body composition, nutritional knowledge, attitudes, behaviours, and future education needs of senior schoolboy rugby players in Ireland. Int J Sport Nutr Exerc Metab 21(5):365-76 